\title{
O QUE FOGE DO OLHAR DAS REFORMAS CURRICULARES: NAS AULAS DE BIOLOGIA, 0 PROFESSOR COMO ESCRITOR DAS RELAÇÕES ENTRE CIÊNCIA, TECN OLOGIA E SOCIEDADE
}

\author{
Antonio Carlos Rodrigues de Amorim*
}

\begin{abstract}
Resumo: 0 artigo analisa os processos de produção de conhecimento escolar em aulas de Biologia nas quais um professor trabalha temáticas dentro do contexto das relações entre ciência, tecnologia e sociedade (CTS). Traz contribuições para a compreensão de aspectos dos fenômenos das reformas educacionais para os quais se faz cada vez mais necessária a incorporação de outros tipos de conhecimentos culturais, tais como os produzidos nas práticas em aula.
\end{abstract}

Unitermos: currículo; ensino de biologia; produção de conhecimento escolar

Abstract: This arti de analyses the process of school knowledge production in Biology classes by teachers who work themes in a science, technology and society context. It contributes to understand aspects of educational reforms and indicates the necessity of incorporation the diversity of cultural knowledges like those produced in dassroom practies.

Keywords curriculum; biology teaching; school knowledge production

\section{0 ensino de Biologia é uma rede tecida nas relações entre formas e con- teúdos}

O s resultados de pesquisas a respeito da educação científica no ensino fundamental e médio vêm apontando, nestas últimas três décadas, para a necessidade de significativas alterações nas já tradicionais interações entre forma e conteúdo que perduram sob matizes variadas no âmbito da prática docente. As vias para essas alterações são múltiplas, como pode ser percebido no quadro abaixo, organizado como síntese geral das temáticas privilegiadas por pesquisadores do ensino de Biologia nos trabalhos apresentados em três congressos nacionais - VI Encontro Perspectivas do Ensino de Biologia (EPEB); I e II Encontro N acional de Pesquisa em Educação em Ciências (EN PEC) - e em teses e dissertações reunidas na obra 0 ensino de Ciências no Brasil: catálogo analítico de teses e dissertações - 1972-1995.

As temáticas privilegiadas nos trabalhos sobre ensino de Biologia de um recente congresso, o VII EPEB, colaboram para evidenciar movimentos que vêm sendo realizados dentro desta área de pesquisa e nas ações educativas. N otam-se as discussões sobre temáticas ambientais associadas ao ensino de temas biológicos de ensino e/ou pesquisa e um crescente aumento do número de trabalhos sobre formação inicial e continuada de professores. No que se refere às questões de aprendizagem, os focos são a construção de representações ou as concepções alternativas aos conceitos científicos por alunos. M as percebe-se também uma ampliação de temas que em encontros anteriores sobre pesquisa em ensino das C iências apareciam pouco destacadamente, tais como as relações entre H istória e Filosofia da Ciência e ensino de Biologia,

* Professor Assistente D outor do D epartamento de M etodologia de Ensino, Grupo Formar - Ciências, Faculdade de Educação, Unicamp. Campinas, SP (email: acamorim@unicamp.br). 
Q uadro 1 - Principais temáticas de investigação sobre o ensino de biologia

\begin{tabular}{|c|c|c|}
\hline VI EPEB (1997) & $\begin{array}{l}\text { C atálogo de teses/ disser- } \\
\text { tações (1972-1995) }\end{array}$ & $\begin{array}{l}\text { I e II EN PEC } \\
\text { (1997 e 1999) }\end{array}$ \\
\hline - educação ambiental & $\begin{array}{l}\text { - educação ambiental } \\
\text { - sua relação com a ecologia } \\
\text { - zoologia } \\
\text { - filosofia da ciência } \\
\text { - representações de natureza }\end{array}$ & $\begin{array}{l}\text { - ambiente } \\
\text { - natureza e educação ambiental }\end{array}$ \\
\hline - materiais didáticos & $\begin{array}{l}\text { - materiais técnico-instrucionais } \\
\text { - materiais didáticos }\end{array}$ & $\begin{array}{l}\text { - concepções/conceitos científi- } \\
\text { cos presentes no livro didático } \\
\text { (saúde, evolução, nutrição vege- } \\
\text { tal e genética) }\end{array}$ \\
\hline $\begin{array}{l}\text { - concepções sobre ciência, cien- } \\
\text { tistas e conceitos de ciência } \\
\text { (evolução, genética, citologia, } \\
\text { botânica) }\end{array}$ & $\begin{array}{l}\text { - construção de conceitos pelos } \\
\text { alunos e professores: saúde, mi- } \\
\text { crorganismos, célula, ser vivo, } \\
\text { animal, genes }\end{array}$ & $\begin{array}{l}\text { - concepções espontâneas dos } \\
\text { alunos e a sua centralidade no } \\
\text { ensino das ciências }\end{array}$ \\
\hline \multicolumn{3}{|l|}{ - construção de conhecimento } \\
\hline $\begin{array}{l}\text { - análises de cursos de formação } \\
\text { continuada e inicial de profes- } \\
\text { sores }\end{array}$ & $\begin{array}{l}\text { - avaliação de cursos superiores, } \\
\text { bacharelado e licenciatura em } \\
\text { biologia } \\
\text { - o papel de disciplinas, como a } \\
\text { prática de ensino e a biologia } \\
\text { educacional, na formação de } \\
\text { professores }\end{array}$ & $\begin{array}{l}\text { - formação de professores (ini- } \\
\text { cial, prática de ensino e conti- } \\
\text { nuada; cursos) }\end{array}$ \\
\hline - linguagem e ensino de biologia & $\begin{array}{l}\text { - papel das fontes de educação } \\
\text { não-formal } \\
\text { - jornalismo científico e os } \\
\text { espaços de museus de ciências }\end{array}$ & $\begin{array}{l}\text { - imagens e ensino de biologia } \\
\text { - linguagens e ensino de biologia }\end{array}$ \\
\hline $\begin{array}{l}\text { - a biologia no trabalho peda- } \\
\text { gógico escolar }\end{array}$ & $\begin{array}{l}\text { - as dimensões sociais e políticas } \\
\text { da prática pedagógica } \\
\text { - planejamento de ensino de } \\
\text { biologia - inovador ou tradi- } \\
\text { cional }\end{array}$ & $\begin{array}{l}\text { - condições para o ensino de } \\
\text { biologia } \\
\text { - vestibular } \\
\text { - mercado de trabalho }\end{array}$ \\
\hline $\begin{array}{l}\text { - novos paradigmas para o ensi- } \\
\text { no da biologia }\end{array}$ & $\begin{array}{l}\text { - modelos de ensino de ciências } \\
\text { - papel da experimentação, das } \\
\text { relações da biologia com o coti- } \\
\text { diano, das interações CTS }\end{array}$ & \\
\hline \multirow[t]{2}{*}{ - sexualidade e saúde } & - educação sexual & \\
\hline & & $\begin{array}{l}\text { - produção do conhecimento bio- } \\
\text { lógico em espaços de educação } \\
\text { formal e não-formal }\end{array}$ \\
\hline
\end{tabular}


as discussões sobre linguagens e ensino da Biologia e a produção de conhecimento escolar em espaços educacionais formais e não-formais (M arandino, Amorim, Kawasaki, 2000).

Aos traçados dos caminhos seguidos nessas pesquisas, gostaria de somar algumas conclusões que Ivan Amaral (1998) tira no artigo em que analisa o currículo das Ciências, nas últimas quatro décadas, em relação àquilo que vem sendo proposto e efetivado em termos de renovação desta área de conhecimento escolar do ensino fundamental. 0 autor focal iza mais os aspectos epistemológicos, uma vez que escolhe as concepções de educação, ambiente e ciência como possíveis estruturantes da metodologia do ensino de Ciências. A dimensão epistemológica é muito privilegiada nas pesquisas em ensino de Biologia, como pode ser percebido no Q uadro 1. U tilizo seus dados neste texto para extrair os elementos que vêm configurando a metodologia de ensino na área de Ciências. Escolho um trecho de seu trabalho para situar como ocorreram mudanças na compreensão do ensino de Ciências, uma vez que foram captadas tendências reformuladoras das concepções de educação, ambiente e ciência. 0 autor cita como características derivadas desse processo

flexibilidade curricular; interdisciplinaridade; desenvolvimento de uma visão sistêmica de ambiente; conscientização da necessidade de preservação da natureza e do uso racional dos recursos naturais; formação de uma imagem de ciência como atividade humana historicamente determinada; articulação entre o senso comum eo conhecimento científico; respeito ao conheci mento prévio e às estruturas cognitivas do estudante; correlação entre psicogênese e história da ciência; incorporação do cotidiano ao processo de ensino-aprendizagem; construção do conhecimento pelo aluno. (Amaral, 1998, p.220)

As características descritas por Ivan Amaral são derivadas de diferentes discursos construídos pela Academia em seus trabalhos de pesquisa e ensino. Tais características são transformadas, por exemplo, na elaboração de diretrizes e propostas curriculares, como é 0 caso dos Parâmetros Curriculares N acionais (PCN), foco de análise no artigo de Amaral. Os PCN foram produzidos a partir da análise de vários elementos, dentre eles, as propostas curriculares elaboradas pelos diferentes estados do Brasil. No caso do ensino de Ciências, das 21 propostas analisadas pela Fundação C arlos $\mathrm{C}$ hagas, I van Amaral destaca algumas características evidenciadas e que nortearam a proposição final quanto à organização das temáticas (conteúdos) - Educação Ambiental, Educação em Saúde e Educação Tecnológica - assim como de princípios metodológicos (formas) - cotidiano como ponto de partida; usar do conhecimento prévio do aluno; levar em conta o contexto histórico-social; tomar a natureza como laboratório; servir-se de uma metodologia ativa; interdisciplinaridade; visão globalizante da Ciência; relação entre ciência, tecnologia e sociedade.

Já em seu trabalho, M aria Lúcia Wortmann (1998) focaliza a história do ensino das Ciências, já contada e recontada por vários autores. Coloca, entretanto, no centro das atenções as práticas consideradas e configuradas como tradicionais dentro do ensino das Ciências. Escolhendo os documentos oficiais produzidos para a reforma do ensino de Ciências das dé cadas de 60 e 70 no Brasil, e inspirando-se na obra de Thomas Popkewitz (1994), examina "contingências e relações estruturais que têm conduzido a construção de discursos hegemônicos para esta disciplina escolar, sem pretender levar à organização de outras 'regras' e 'padrões de verdade' para substituí-los" (p.131). Em uma das conclusões de seu trabal ho, a autora argumenta que 
tanto a escola como os textos escolares vêm promoven do sel eções e organizações na forma como adotam as "especifici dades pedagógi cas" ... em função e a partir de sistemas particulares de idéias e regras de raciocínio que estão entranhados nas práti cas escolares. N este senti do as "especifi cidades pedagógi cas" adquiri ram funções e dimensionamentos até diferentes daqueles que os seus/suas idealizadores Ihes tinham conferido: elas foram alteradas no processo de escolarização, embora continuem a caracterizar uma época e um estilo de pensamento. (p.154)

Parece-me que, na escolha das relações entre conteúdo e forma como uma categoria importante e interessante para analisar o ensino das Ciências, o dimensionamento de conteúdo e de forma que se faz conceitualmente circunscreve-os como conteúdo científico e como formas de sua abordagem, muitas vezes atreladas a metodologias específicas de produção de conhecimento em cada área científica. D essa forma, as aulas de laboratório, o método de ensino por projetos, a investigação da prática científica a partir do método científico discutido em suas dimensões epistemológicas, históricas e sociológicas, são objetos de interesse tanto nas escolas de educação básica e em órgãos políticos e pedagógicos que os têm como parâmetro para melhoria ou inovação, quanto nas universidades, que sobre eles se debruçam na produção de suas pesquisas. G ostaria de destacar que as pesquisas acadêmicas sobre o ensino de Ciências têm privilegiado como focos temáticos para investigação problemas associados intensamente a essa "tradição do ensino de Ciências", como se percebe a partir dos resultados do trabalho de Jorge M egid N eto (1999), assim como no Q uadro 1, excetuando-se abordagens mais recentes como alguns trabal hos sobre linguagem e imagem no ensino de Biologia e sobre a produção do conhecimento escolar.

\section{Formas e conteúdos se organizam nas matrizes do contexto CTS}

Q uando realizei a pesquisa de mestrado (Amorim, 1995), e analisei as relações entre ciência, tecnologia e sociedade (CTS) que se encontram presentes no currículo de Biologia do ensino médio, mais especificamente, nas práticas e discursos de oito professoras. Ficou-me muito presente a reflexão sobre as relações entre conteúdo e forma no ensino da Biologia. Inquietaram-me as questões que circunscrevem a metodologia do ensino das Ciências, tanto as que fazem parte de uma certa tradição neste ensino quanto as que rompem e propõem algo "novo", como é o caso do movimento CTS.

Constatei que existem abordagens diversificadas sobre as relações CTS no espaço curricular da escola de nível médio, acontecendo na maioria das vezes entremeadas por uma dicotomização da relação entre teoria e prática, que pode ser analisada como agente de quebra da unidade entre forma e conteúdo, assim como derivada, necessariamente, das diferentes associações entre forma e conteúdo que as professoras constróem no seu trabalho pedagógico. Por exemplo, reconheci, com os resultados da pesquisa de mestrado, que os el ementos ciência e tecnologia ( $C \& T$ ) não são contextualizados em uma específica sociedade, o que geralmente não leva a um desenvolvimento da capacidade crítica dos alunos frente aos diferentes papéis da $C \& T$, a fim de lhes garantir tomadas de decisão mais conscientes. U m outro aspecto diz respeito às estratégias utilizadas pelas professoras, no trabalho com os alunos, que oferecem pouca possibilidade para que eles venham a modificar concretamente a sua realidade, a partir de uma resignação das relações CTS.

Analisando hoje a escol ha, na referida pesquisa de mestrado, da relação entre pesquisa e ensino e da relação entre aulas teóricas e aulas práticas como instâncias para organização dos 
dados coletados, penso que uma discussão mais abrangente sobre as interações CTS poderia ser desenvolvida, tanto por privilegiar quanto por redimensionar as formas já presentes na prática docente, a partir das quais se consegue construir novos conteúdos.

Posso supor, pela análise realizada na pesquisa de mestrado, que é na prática social do trabalho pedagógico que se modelam as formas a relação entre pesquisa e ensino e a relação entre aulas teóricas e aulas práticas. Estas se interligam a diferentes conteúdos e formas oriundos de outros espaços sociais e culturais, com os quais estabelecem diálogos e travam movimentos de resistência às ideologias subjacentes ou de reprodução das mesmas. 0 u, fazendo-me mais claro, pela análise das práticas e dos discursos das professoras de disciplinas biológicas, é possível identificar que as interações entre forma e conteúdo presentes em aula constróem perspectivas para a metodologia do ensino das C iências que fogem daquelas que mais tradicionalmente têm sido exploradas nas propostas de inovação curricular que, por exemplo, geralmente argumentam que as formas são expressões externas da lógica dos conteúdos. M etodologicamente procurei na pesquisa conhecer o que já existia nas práticas escolares sobre CTS e encontrei distanciamentos daquilo que é proposto/enunciado como inovador pelas correntes reformistas.

0 contexto CTS para o ensino das Ciências exige a incorporação de dimensões múltiplas dos conhecimentos científicos, uma vez que é nas práticas sociais que são trabalhados os aspectos teórico-práticos de $C \& T$. Especificamente às questões relativas às relações entre teoria e prática que mapeiam o contexto CTS, um conjunto de elementos são apresentados, em números monográficos de duas revistas de circulação internacional: Therory into Practice (v.30, n.4, 1991; v.31, n.1, 1992) e revista I beroamericana deEducación (n.18, 1998). D os diferentes artigos em que se discutem as relações CTS no ensino de Ciências, identifiquei três agrupamentos que trabalham os seguintes enfoques: reforma educacional e currículo oficial (Aikenhead, 1992; Beagaw, 1992; H urd, 1991), aspectos epistemológicos da ciência e do ensino das Ciências (Carter, 1991; Brunic, 1992; Becerra, 1998), formação de professores para as práticas de ensino no contexto CTS (Bybee, 1991; Fullick, 1992).

Gostaria de situar o presente trabalho em um território no qual imbricam elementos desses três agrupamentos, mas que são remodelados por um ol har de fora, de exterioridade, que busca os conhecimentos produzidos por professores ao ensinar Biologia num contexto CTS, nas práticas cotidianas das aulas. N este artigo, investigo as maneiras como se configuram as dinâmicas de estabelecimento dos conhecimentos escolares em uma arena de interrelações na qual se apresentam ou disputam conteúdos de vários campos culturais.

Pareceu-me instigante analisar o conhecimento escolar a partir das relações entre forma e conteúdo, para conhecer melhor seus múltiplos aspectos. D ebrucei-me sobre os dados coletados em um curso de formação de professores de Ciências, rica fonte de inspiração. D ecidi experimentar, no ano de 1997, um tipo diferente de curso, pelo menos para mim, no qual seria tratado especificamente um tema do currículo tradicional do ensino de Ciências, o corpo humano. 0 curso se propunha a abordá-lo em dimensões que geralmente são ausentes da cultura escolar, tais como o seu contexto social mais amplo enão atrelado exclusivamente às temáticas da saúde, bem como as fundamentadas na $\mathrm{H}$ istória e Filosofia da Ciência. ${ }^{1}$ As interações entre forma e conteúdo que se configuraram durante o desenvolvimento do curso sobre corpo humano abriram perspectivas para discussões, por exemplo, sobre as representações culturais do corpo, a relação homem/máquina, o conhecimento científico na área de fisiologia humana e

$1 \mathrm{M}$ aiores detalhes a respeito deste curso e do redimensionamento metodológico, pautado nas relações CTS, para trabalho com temáticas sobre o corpo humano, ver Amorim (1998a, 2000b). 
a construção hegemônica da representação de corpo fragmentado. Percebi que a dimensão cultural do corpo rompe com a perspectiva criada pela estética científica, por vezes positivista, que ordena e lineariza. Já a tecnologia reconta e reinventa a história de nosso corpo: corpos vestidos, corpos-mercadorias, corpos prevenidos contra contatos externos.

Tinha, também, a intenção de possibilitar aos professores 0 acesso a uma forma diferenciada do conteúdo científico sobre o corpo humano que, dentro da trajetória que construí, apresentava certas características de inovação. Esse curso fez parte das orientações técnicas de uma das $D$ elegacias de Ensino da cidade de Campinas. H avia um forte interesse do corpo técnico de apoio pedagógico em saber o que as/os professoras/es estavam levando do curso para as sal as de aula. Considerei também necessário recolher indícios a respeito de vários itens: a forma como os professores trabalham em aula; o conteúdo de que se apropriaram no curso; de que maneiras vinham construindo a sua própria metodologia; quais eram as preocupações relativas ao conteúdo de corpo humano para as quais vinham tentando encontrar respostas na prática pedagógica; que seleções faziam do conteúdo apresentado no curso.

Essa necessidade nasceu de outra: a aval iação ensejada pela D el egacia de Ensino e de al gumas situações de trabal ho no curso, nas quais os professores sinalizavam a importância, na organização de atividades em ensino de Ciências, de características de seus saberes profissionais (ou da experiência), tais como o estímulo aos alunos, as condições materiais da escola, 0 tempo escolar para o desenvolvimento das atividades, o número de alunos por sala etc.

Consegui mais detalhes da trajetória metodológica de um dos 23 professores que vinham acompanhando o curso. Chamo-o, neste texto, de professor Edson. As atividades que utilizou em aula foram objeto de minhas leituras atentas em busca das relações entre forma e conteúdo que foram construídas. Após a leitura e a análise das atividades, entrevistei-o, buscando esclarecimentos e pistas para maiores aprofundamentos. ${ }^{2}$

No dia em que solicitei que fossem elaborados os relatos, o professor Edson escreveu: "O s textos foram utilizados na íntegra. H ouve também da minha parte uma adaptação de acordo com os al unos que trabal ho. O s textos na minha opinião são ótimos". Chamou-me a atenção como o professor indica que fez uma transformação do material com que teve contato no curso, adaptando-o. Q ue tipos de adaptação foram essas? $Q$ uais as relações que teceu entre conteúdo e forma? Q ue relações foram estabelecidas com a metodologia apresentada no curso? Fui em busca de respostas para estas questões.

\section{0 contexto das práticas: escola, professor, alunos e aula pelo olhar do professor}

Convido o leitor a entrar no universo escolar desenhado pelo professor Edson em sua entrevista. Seus anseios, sua relação com os alunos e com os novos conhecimentos, a caracterização dos alunos são personagens e cenários no qual movimentou-se, teve vida, o roteiro com as suas atividades.

O s alunos com quem trabal ha são de curso noturno, trabalhadores que residem em bairro periférico de $C$ ampinas e estudam em escola pública sediada nesse mesmo bairro. De acordo com o professor, os al unos estavam, em sua maioria, na faixa etária que geralmente é considerada a adequada para a 1ạ e $3^{a}$ série do ensino médio, fato que lhe causou espanto, pois pressupunha que alunos do noturno seriam mais velhos.

2 Esse trabalho de análise da produção do professor Edson é um dos fios, fragmentos, que marcam as origens da minha pesquisa de doutorado (Amorim, 2000a). 
Edson,

A escola onde lecionou nos anos de 1996 e 1997 é, nas considerações do professor

muito boa, porque tem estrutura. Você tem apoi o para quem faz oficina, desenvolve projeto na escola. A diretora dá todas as condições para isso ... Tem estrutura física, material, dentro do possivel. Tem material para a gente trabalhar. Isso era bom na escola. É uma direção que acompanha o que você está fazendo, incentiva, eisso ébom para o professor. ${ }^{3}$

0 ol har do professor Edson sobre a escola capta também as regras disciplinares e de comportamento tanto dos professores quanto dos alunos como sendo marcas que a qual ificam como boa. "A escola é uma escola que tem muita regra, vamos dizer assim, regrinhas. E essas regrinhas vão condicionando os al unos a se comportarem bem em aula. Então tem muita regra mesmo", diz enfaticamente. Existem, por exemplo, vários sinais que indicam a hora de cada personagem da escola entrar na aula. Isso o professor julga como sendo bom, pois disciplina, e "sem disciplina não dá, ainda mais na idade dos alunos, não é?" Agora, quando a disciplina relaciona-se com o estabelecimento de regras que governam as ações do professor, "tem que ter expressão, tem que ter postura, isso às vezes me irrita, ter postura. ... E você não pode fazer isso, fazer aquilo, não pode fumar na frente do aluno, isso aí me irrita". Porém, essa sua reação de irritar-se convive, aparentemente de forma pacífica, com a necessidade de a profissão do professor ser disciplinada, com hábitos e regras esperados para o professor, pois "já existia um mito de o professor ser o exemplo para o aluno. $N$ em sempre é, mas deveria ser ... Às vezes eu fico pensando nisso: professor deveria ter que ir de gravata, de social, para dar aula: é um profissional". E ser o exemplo passa pelos campos do vestuário, da postura e da cultura, necessariamente diferenciados e melhores do que os dos alunos. E, claro, não posso me esquecer, do campo do conhecimento:

0 professor precisa saber mais do que 0 aluno, primeiro porque ele é mais velho. N ão digo apenas nas partes específicas, digo no âmbito geral, das coisas da vida. Tem que saber mais. Como é o primeiro dia de um serviço, como é que acontece aquilo. Isso existe: pela idade, tem que saber mais.

Essas idéias representam uma interlocução que faz com a sua experiência na família, na qual se tem a "expectativa com relação a outras pessoas. Por exemplo, dentro de casa, com relação a seus pais ou irmãos mais velhos, você tem essa expectativa de que eles saibam mais do que você". Esta visão hierárquica, respaldada pela idade, confere ao professor Edson uma aposta muito grande de que a experiência de vida dará respostas mais rápidas para a resolução de problemas.

0 magistério representa para o professor Edson, nesse momento, uma condição privilegiada de trabalho, pois o horário é bastante flexível e o salário, na média do mercado, não está desprezível. A isso se associa o fato de não querer retornar ao trabalho como marceneiro (sua primeira experiência profissional) e nem ao trabalho burocrático em escritórios. Porém, não quer mais trabal har na rede estadual, pois, de acordo com o ele, não há incentivo para aqueles que trabalham diferenciadamente e, pior, "o Estado vai deixando as pessoas medíocres. Privilegia quem sabe menos e quem faz menos". Com as diretrizes administrativas

${ }_{3}^{3}$ Este e demais trechos são de entrevista realizada por mim com o professor Edson no dia 24/04/98. 
e pedagógicas implementadas na rede estadual de educação básica, não foram atribuídas classes no ano de 1998 ao professor Edson. Essa conjuntura política, que excluiu o professor do campo de trabal ho, o desanima e reforça sua interpretação de que o trabalho diferenciado qualitativamente não tem valor na rede estadual de educação.

0 investimento que fez ao cursar a licenciatura em Ciências Biológicas - "o curso de Biologia dá a impressão de ser um colegial mais forte"4 - não pode esperar mais tempo para ter o retorno. Esta forma de pensar é qualificada pelo professor Edson como sendo "prática" e é uma das marcas fundamentais na organização de seu trabalho em aula.

Um dos aspectos de "ser prático", na vivência do professor, é levar rapidamente para a aula aspectos aprendidos nos cursos da U niversidade e em outras instâncias, como a 0 ficina Pedagógica. Sua atenção nos cursos está voltada para a elaboração de formas de associar os conhecimentos adqui ridos com atividades e re-elaborações necessárias para sua adequação na aula. Essa re lação entre teoria e prática foi um aprendizado que teceu durante a sua vivência simultânea como professor de Biologia e Ciências e aluno do curso de licenciatura. Sentiu falta desse movimento, após a graduação, buscando, então, projetos e cursos nos quais poderia continuá-lo. Esse fato é muito importante para compreender as atitudes de inovação em alguém que tem tão cristalizadas variadas visões da escola, se aproximando de aspectos fortes da tradição escolar, como a disciplina, a autoridade do professor como detentor de maior conhecimento, as expectativas quanto a tipos de aprendizagem dos alunos etc. Também julgo ser relevante destacar a importância da formação continuada dos profissionais de educação, que pode representar o espaço para discussões, reflexões e criações metodológicas ou de quaisquer outras naturezas, além do estímulo à inovação curricular.

0 professor Edson guarda-se ao direito de se assustar com atitudes, principalmente dos alunos, que podem desmontar seus preconceitos a respeito de interesses e envolvimento deles. Em al guns momentos, alunos o surpreendem, pois jugnado-os apáticos e desinteressados, acha impressionante o fato de terem trabalhado. "Como é que pode? 3o ano! Eu até pensei que eles fossem ignorar este tipo de serviço." 5

As experiências que considera como de sucesso na sua relação com os alunos e a disposição de levar de imediato para aula informações e vivências, que teve principalmente em cursos, estimulam o professor a se aventurar metodologicamente, tecendo caminhos muito interessantes, como as adaptações que fez a partir das atividades originais desenvolvidas no curso na D elegacia de Ensino.

\section{A aula é invadida pelas relações entre biologia, tecnologia e cultura ${ }^{6}$}

Eu passo muita matéria na aula. Eles escrevem bastante, mas na explicação eu não [me] alongo. Eu acho que não vale a pena! Chegava na aula, batia o sinal,

\footnotetext{
${ }^{4}$ Sobre como avalia a sua formação universitária, o professor Edson diz o seguinte: "Eu acho que a formação dentro da faculdade deveria ser diferente. Porque quem não sabe mexer em computador, quem não sabe - eu não se - falar inglês... Tem que saber falar inglês, tem que ler jornal todo dia, tem que ver jornal todo dia, tem que ouvir rádio todo dia, porque, ao chegar na aula, 0 aluno que fez isso, vai saber mais do que você. $N$ ão é só saber aquele específico só da Biologia, tem que saber o que aconteceu fora da Biologia, para fazer comparações. A formação de professores nesta área está fora de foco, porque normalmente o que é dado é só aquilo, só a matéria. E não dá para ser um bom professor sabendo só aquilo. I gual no caso da sua oficina, você falava de filosofia, filosofava sobre um assunto relacionado à Biologia, uma coisa que eu nunca tinha pensado, você falava de história da biologia...

5 Trata-se de uma atividade sobre cariótipo organizada na forma de encarte pela Editora M oderna e disponibilizada para os professores.

6 U ma versão preliminar deste item foi apresentada na 21a Reunião Anual da AN PED (Amorim, 1998b).
} 
eu passava coisas na lousa, os alunos entravam, copiavam, eu explicava o que estava na lousa. No máximo dez minutos, 0 assunto é esse, é isso. Passava de dez, estava falando outras coisas, que não tinham nada a ver. ... Essa era a minha característica: coisas bem práticas, resumidas, sem muita teoria, porque não adianta nada, 0 aluno não vai aprender nada. U m coisa bem simples, eu resumia tudo.

Essa foi a maneira como o professor Edson narrou a sua aula, iniciante no magistério, com a experiência de três anos. Buscando o significado da praticidade que atribui ao seu trabaIho, encontrei em suas falas o ser prático como um ser capaz de discernir o que serve ou não para o espaço e o tempo da aula, particularmente 0 que possa ser utilizado ou aprendido de imediato. C aracteriza o espaço da aula como um espaço que exige respostas rápidas para manter 0 interesse dos alunos e para a manutenção da disciplina - especialmente numa época em que se ameaça a avaliação como um instrumento disciplinador, de manutenção da atenção e de interesse dos alunos nos conhecimentos que compõem o currículo oficial das escolas cujo transmissor, pela autoridade que já lhe é conferida socialmente, é o professor. Isso porque não tem outros atrativos para os alunos, como o laboratório de Ciências, característica que atribui como sendo específica no trabalho do professor de Biologia/Ciências. Pois bem, é nesse contexto que o professor Edson desenvolveu várias atividades em aula e que, de alguma maneira, relacionam com o curso que fez nas orientações técnicas. D eu-lhes um caráter prático, seguindo as características que marcam as suas aulas tanto na disciplina de Biologia quanto na de Saúde Pública.

U ma primeira atividade - sobre "o corpo humano no contexto social" - baseou-se em outra homônima apresentada no curso. As tabelas e as questões foram as formas que o professor escolheu para que os al unos trabalhassem com necessidades do corpo humano, relacionando-as à biologia e à cultura. A separação entre biologia e cultura é proposital na organização da atividade e tem como intenção problematizar as aproximações entre as culturas científicas (biologia) e outras culturas nas representações sobre o nosso corpo.

\section{"Nosso corpo é a fusão do biológico com o cultural"}

Atividade: Utilizando você como exemplo e comparando com as demais pessoas que estão na aula, complete a seguinte tabela.

\begin{tabular}{|l|l|l|}
\hline $\begin{array}{l}\text { Necessidades do corpo } \\
\text { humano }\end{array}$ & Elemento biológico & Elemento cultural \\
\hline 1. Ver & & \\
\hline 2. Comunicar & & \\
\hline 3. Respirar & & \\
\hline 4. Sentir & & \\
\hline 5. Alimentação & & \\
\hline 6. Locomoção & & \\
\hline 7. Proteção & & \\
\hline 8. Reprodução & & \\
\hline $\begin{array}{l}\text { 9. Adaptação às } \\
\text { condições ambientais }\end{array}$ & & \\
\hline 10. D efecar & & \\
\hline 11. Limpar & & \\
\hline 12. D escansar & & \\
\hline 13. Aprender & & \\
\hline
\end{tabular}


a) Para que ou por que foram criados os elementos culturais?

b) Q uais os pontos positivos e negativos que o elemento cultural traz para o nosso corpo?

c) Quais as possíveis doenças que surgiram em decorrência do aperfeiçoamento do elemento cultural?

Realizando uma das possíveis leituras do trabalho do professor, vislumbra-se que ele transformou a tabela original, ampliando a quantidade de necessidades do corpo humano para as quais os alunos deveriam encontrar elementos biológicos e culturais. Acrescentou necessidades como a de aprender, muito ligada a uma tentativa de destacar a função social da escola, e as de limpar e defecar, associadas a práticas de higiene e saúde, o que se justificaria, em princípio, pelo fato de ter produzido esta atividade para desenvolvêlas em aulas de Saúde Pública.

Pelas questões elaboradas, o professor - dando uma forma de abordar o conteúdo "corpo humano como fusão do biológico com o cultural" - propõe para os alunos que, em grupo, reconheçam algumas relações conflituosas entre 0 elemento cultural e 0 elemento biológico no atendimento a necessidades do nosso corpo. Cria uma situação em que o ele mento cultural distorceria as funções naturais do corpo e conduz à necessidade de discussão ou levantamento da problemática relacionada ao seu impacto em nossas vidas, por exemplo ao propiciar 0 aparecimento de doenças. $\mathrm{N}$ as questões que formulou, é perceptível que o professor as organizou de modo que os al unos pudessem discutir e avaliar o poder dos elementos culturais em nossa sociedade. Tal avaliação não coube explicitamente ao conhecimento científico, uma vez que privilegia a análise de outros fatores culturais (mas não-científicos) que delineiam a representação de corpo humano. A percepção biológica "naturalizada" do nosso corpo parece estar isenta de avaliação quanto aos aspectos positivos e negativos que dela se derivam.

Em outra atividade o professor retoma a discussão dessa relação entre biologia e cultura, ao tratar de doenças que tenham causas sociais diversas. Assim o professor organizou a atividade que denominou "População e meio ambiente", na qual atenta para a problemática dos seguintes aspectos e conflitos causados pela superpopulação: doenças, fome, guerras e sobrevivência do mais forte.

Criada de forma original pelo professor Edson, esta atividade não representa uma seleção, um recorte similar, de formas e conteúdos abordados que já tivessem sido apresentados no curso. Relacionam-se, entretanto, a perspectivas metodológicas mais amplas do curso, como as interações CTS.

\section{"População e meio ambiente"}

a) Q uais as principais doenças que surgiram em decorrência do aumento da população mundial?

b) Q uais são as maneiras de evitar uma explosão demográfica?

c) Através desses fatores, podemos dizer que nosso corpo depende da nossa relação com a sociedade?

d) Q uais as doenças que talvez não tivéssemos, se vivêssemos em uma sociedade sem conflitos?

\begin{tabular}{|l|l|l|}
\hline D oença & Ó rgão(s) afetado(s) & C ausa cultural \\
\hline & & \\
\hline
\end{tabular}

e) De que maneira a sociedade conseguiu erradicar ou amenizar certas doenças que ela mesma causou? 
Compartilhando a opinião de ser necessário tratar das relações do corpo humano com a sociedade, o professor Edson estrutura a atividade de tal forma que a partir de um problema social - a superpopulação - estimula os alunos a discutirem as causas desse problema e suas consequêencias (por exemplo, doenças), associando-o a uma sociedade em conflitos (com diferenças de classe, de renda, com guerras e disputas de poder). Percebe-se facilmente que define a sociedade com a qual o corpo humano tem dependência: a sociedade capitalista.

Se, dentro do espaço da aula os professores e os alunos são autores de um conhecimento, considero pertinente abordar o papel do professor Edson nesse processo, dentro da me táfora do escritor progressista, definida por Walter Benjamin (1985), como sendo aquele cuja decisão se dá no campo da luta de classes, na qual se coloca ao lado do proletariado; daí sua autonomia de autor, sua produção estar ligada a interesses de classe. A produção de que é autor situa-se, pois, dentro das relações de produção de uma determinada época. Parece-me importante resgatar o papel do professor como autor e produtor de conhecimento, principalmente em um contexto que o tem alienado de se reconhecer como tal, situação que, quando descoberta, causa-Ihe estranhamento, mas ao mesmo tempo traz-Ihe lembranças de ações críticas.

Pesquisador: Essa outra atividade ["População e meio ambiente"] foi originalmente criada por você?

Edson: [espanto] Essa daí não tem nada a ver com a sua oficina? [curso oferecido na D elegacia de Ensino]

Pesquisador: Essa daqui você montou a partir de coisas que Ihe chamaram a atenção. $\mathrm{N}$ ão foi oferecida no curso com esse formato.

Edson: M as isso não tem em livros didáticos. Eu nunca vi em livros didáticos uma abordagem que compare o lado específico - corpo - com a sociedade. Q ue eu saiba não tem. Só se tem e... Eu lembro bem. Vi num livro o item "Sociedade e meio ambiente", e tinha 3 parágrafos, [risos] só isso! [risos] Pensei nisso daí, nesses temas que tinham no livro: meio ambiente, fome, doenças e guerras, que são as três mais evidentes para a gente. Aí olhando o quadro, eu criei este aí, sempre relacionando com sociedadetambém. Relacionei com a sociedade o que causava doença, fome e guerra. Só que eu falei - aqui eles fizeram muita coisa - no biológico, na causa cultural... Foi muito difícil. Vai num crescente: encontrar a doença é fácil, o elemento biológico é mediano, a causa cultural é difícil. ${ }^{7}$

Percebo que o professor Edson apresenta uma iniciativa de aproximação do homem com a sociedade pela vertente do equilíbrio populacional - conceito clássico dentro da Ecologia. Concebe uma separação do homem com a sociedade, separação extrapolada para o corpo humano e a cultura. Também nessa atividade, ressalta a residência do problema nas causas culturais, apesar de oportunizar a discussão da contradição existente nas práticas culturais que, ao mesmo tempo que geram doenças, podem erradicá-las ou amenizá-las.

Ao transpor abordagens que vinculam o corpo humano com a sociedade para o currículo formal das escolas - por exemplo, articulando-as com os temas de Ecologia - o professor Edson inova no sentido de levar para aulas de Biologia contextual izações específicas para a sociedade capitalista. Articula referenciais metodológicos marcadamente biológicos e outros culturais para análise do ambiente, a partir dos quais propõe uma explicação da sociedade. Por exemplo, cita que os conflitos causados pela superpopulação levam à sobrevivência do mais

7 Entrevista realizada em 20/04/1998. 
forte, aplicando interpretação do princípio da luta pela sobrevivência e de seleção natural na compreensão de aspectos sociais. Reforça, por outro lado, que todo e qualquer elemento cultural écausa de desequilíbrios, como doenças, guerras, possivelmente porque tal el emento não caiba na interpretação biológica, "natural" das relações de vida entre os seres.

U ma última atividade a ser apresentada representa um exemplo claro do processo de seleção real izado pelo professor na sua metodologia, resultando em ações em aula, que têm o aluno como elemento chave de acordo com o próprio professor. Como os alunos (ou a repre sentação que o professor tem deles) condicionariam essas adaptações? Aproximar da sua realidade, poderia ser uma suposição - eis, novamente, os tópicos ligados à saúde utilizados para resolver essa necessidade. 0 utra solução seria diminuir o tamanho do texto para poder trabaIhá-lo dentro do tempo escolar, do ritmo de leitura dos alunos, das condições de trabal ho que não permitem a reprodução, via xerox, dos textos, tendo que copiá-los no quadro ou ditá-los. $M$ as o que ficou da seleção feita ao reduzir o texto original? Por que al guns elementos foram suprimidos e outros permaneceram? Q ue relações têm essas ações do professor com sua repre sentação do papel do aluno dentro do processo de construção do conhecimento escolar?

Podemos encontrar respostas para essas perguntas analisando como 0 professor organizou as atividades abaixo para trabalhar com seus alunos.

\section{Texto original: "O corpo humano e a sociedade"}

0 nosso corpo pode ser visto, para fins de estudo, sob diversos pontos de vista. U m desses pontos de vista é o da ciência, que descobriu uma série de coisas que hoje são de conhecimento de várias pessoas, por exemplo: médicos. 0 estudo do nosso corpo, no campo das Ciências, éreal izado por cientistas na área de Anatomia H umana (estuda os órgãos do corpo humano), na área de Fisiologia H umana (estuda o funcionamento dos órgãos do corpo humano), na área de Citologia e Bioquímica (estudam a parte microscópica do corpo humano), na área de H istologia (estuda os tecidos que formam o corpo humano), na área de $G$ enética (estuda as informações hereditárias que passam de pais para filhos), na área de Paleontologia e Evolução (estuda corpos de seres humanos que viveram em outras épocas), na área de Fisioterapia, na área de Antropologia (estuda as relações sociais dos seres humanos), na área de $D$ ança, na área de Teatro, na área de Educação, dentre tantas outras. Então, o corpo humano não se restringe apenas ao estudo dentro da Biologia; existem informações de outras áreas.

O corpo humano aparece, por exemplo, como inspiração para artistas plásticos e escultores, para fotógrafos, para músicos, para poetas etc. Além desse lado mais romântico, o corpo humano é, também, produto que pode ser vendido, como no caso de prostituição, tanto masculina quanto feminina.

O corpo humano apresenta também o seu caráter político, quando é objeto de discussões em nossa sociedade que tratam de questões de saúde pública (tratamento de saúde, funcionamento dos hospitais, saneamento básico, infecção hospitalar, vacinas e proteção contra doenças, medicamentos etc). 
M esmo que não concordemos com uma visão reducionista que é passada quando comparamos o corpo humano a uma máquina, na atualidade é cada vez mais crescente a possibilidade de se fazerem substituições de órgãos do nosso corpo por outros artificiais ou a utilização de aparel hos que podem auxiliar ou desempenhar uma série de funções fisiológicas. Tais situações mostram bem a interface da tecnologia com temáticas relativas ao corpo humano. Como em qualquer situação que envolve tecnologia, há de se dimensionar tanto os aspectos positivos quanto os negativos de sua utilização, como os que podem ser vistos na sua aplicação na área da Saúde que, se por um lado, podem representar possibilidades de melhorias nas condições de vida, há questões como intoxicação ou contaminação por substâncias utilizadas nas máquinas ou falhas na sua manutenção, rejeição dos órgãos artificiais, dentre outros.

Então, apesar de a gente estudar apenas alguns aspectos do corpo humano, é importante que lembremos sempre que ele não se restringe a cabeça, tórax, abdome, membros e os órgãos internos. Reúnam-se em grupos e levantem exemplos que ilustrem:

a) Como os corpos humanos se comportam em sociedade?

b) Como tentamos em sociedade esconder alguns aspectos do nosso corpo (formas, odores, beleza/feiura etc.)?

c) 0 que é valorizado pela nossa sociedade em termos de qualidades do corpo humano?

\section{Produção do professor Edson: "Abordagens do corpo humano na sociedade"}

0 nosso corpo pode ser visto, para fins de estudo, sob diversos pontos de vista. U m desses pontos de vista é o da ciência, que descobriu uma série de coisas que hoje são de conhecimento de várias pessoas, por exemplo: médicos. 0 estudo do nosso corpo, é realizado por cientistas nas áreas de Anatomia H umana, Fisiologia etc.

O corpo humano aparece, por exemplo, como inspiração para artistas plásticos e escultores, para fotógrafos, para músicos etc. Além desse lado mais romântico, o corpo pode ser vendido, como no caso de prostituição, tanto masculina quanto feminina.

o corpo humano apresenta também o seu caráter político, quando é objeto de discussões em nossa sociedade que tratam de questões de saúde pública (vacinas, medicamentos etc).

D evido a determinadas doenças, é cada vez mais crescente a possibilidade de se fazerem substituições de órgãos do nosso corpo por outros artificiais ou a utilização de aparelhos que podem auxiliar ou desempenhar uma série de funções fisiológicas.

Perguntas:

a) D e que maneira o texto aborda nosso corpo? 
b) N osso corpo existe de maneira fragmentada?

c) É realmente nosso corpo comparado a uma máquina?

Atividade:

a) Como os corpos humanos se comportam em sociedade?

b) Como tentamos, em sociedade, esconder alguns aspectos do nosso corpo (formas, odores, beleza/feiura)?

c) 0 que é valorizado pela nossa sociedade em termos de qualidades do corpo humano?

Fica evidente que o professor, ao suprimir al gumas partes do texto original, selecionou ítens que julgou mais importantes. M udando também o título do texto de "O corpo humano e a sociedade" para "Abordagens do corpo humano na sociedade", o professor reorganiza três parágrafos que apresentam idéias ligadas à abordagem científica, à abordagem social e à abordagem tecnológica do corpo humano. A partir da seleção de trechos específicos do texto original, dá ao novo texto uma forma que possibilite perceber o enfoque CTS nesse conteúdo.

É interessante ressaltar que o professor Edson leva para discussão em aula três pontoschaves dentro da metodologia que apresentei no curso, que são as diferentes representações do corpo humano, a questão da fragmentação do nosso corpo, a comparação do corpo com a máquina. Inclui tais aspectos na forma de questões, que não estavam presentes na atividade original.

Ao fazer a seleção a partir do texto originalmente apresentado e discutido no curso, o professor escolhe a concepção de ciência como sendo equivalente apenas à área de conhecimento biológico, especificamente a fisiologia e anatomia humanas. Vincula, pela saúde, a relação entre corpo humano e sociedade, selecionando, dentre os diferentes aspectos que conferem a dimensão política do corpo humano ${ }^{8}$, aqueles que ressaltam a existência de tecnologias para beneficiamento da população, excluindo as percepções mais claras da saúde como um bem coletivo (saneamento básico, por exemplo). Por sinal, ao escolher vacinas e medicamentos como exemplos da interface tecnológica da ciência com a sociedade, aproxima-se da hege monia presente nos materiais didáticos, conforme pude identificar em minha pesquisa de mestrado. Aspectos mais polêmicos e que suscitariam, teoricamente, uma discussão a respeito da transformação da realidade foram excluídos. Aos alunos, ao que parece, coube 0 acesso à informação, de uma forma mais crítica, certamente.

Percebi que o professor Edson rompeu os "enquadramentos das telas e janelas" 9 que conferi à metodologia que construí. Isso pode indicar o "remoto controle"10 que existe nas interações entre forma e conteúdos características de uma proposta de ensino quando esta é aplicada, desenvolvida em outro campo, como as diferentes salas de aula de nossas escolas.

0 professor Edson construiu em aula movimentos a partir de processos de seleção, reorganização, reprodução das atividades originais. A proximou as atividades originais da realidade dos alunos possibilitando, no trabalho em aula, o diálogo entre a ciência e a cultura, de modo a diminuir certa estranheza ou um assombro. Elaborou contextualizações específicas dos temas trabal hados dentro da sociedade capitalista, destacando a individualidade, a competição, a luta pela sobrevivência e os conflitos sociais.

\footnotetext{
${ }^{8}$ C hamo de dimensão política do corpo o conjunto de práticas sociais, particularmente as de gerência pública, que para serem instituídas lançam mão de representações do corpo humano configurando-o, por exemplo, como algo que necessita de higienização, de atendimento hospitalar, de horas de trabalho e de lazer etc.

9 Parafraseando Adriana Calcanhoto na música Esquadros.

10 Idem.
} 
Buscando compreender os processos da construção metodológica que o professor Edson fez nas suas aulas aproximei-me de al gumas discussões dentro do campo do currículo que, particularmente, vêm tratando da relação entre saber, poder e conhecimento escolar. Especialmente foi importante o contato com o trabalho deT homas Popkewitz (1994). Considerando as ações do professor como se constituindo em formas de regulação social, ${ }^{11}$ percebo que nas re lações entre forma e conteúdo, prioriza-se a produção de um conhecimento particular sobre 0 modo como os alunos tornarão o mundo inteligível. Segundo Popkewitz, essa organização do conhecimento corporifica formas particulares de agir, sentir, falar e ver o mundo. Trata-se, também, de um novo conhecimento nascido ou evidenciado nas relações que se estabelecem na aula.

Com esse referencial, aprendo que a seleção de conhecimento implica não apenas informação, mas regras e padrões que guiam os indivíduos ao produzir o seu conhecimento sobre o mundo. $\mathrm{N}$ a forma como o professor Edson organizou as atividades para seus alunos, as regras e os padrões da ciência é que regularão, sem contestação, os seus caminhos de reflexão e ação prática, além de disposições e consciência do mundo social. Pois ele privilegiou a análise avaliativa dos fatores culturais (mas não-científicos) que delineiam a representação de corpo humano. Fica também a impressão de que um olhar crítico que os alunos teriam sobre as ações culturais do homem reconfiguraria a percepção do que é o nosso corpo e o quanto ele está impregnado e submisso a aspectos culturais. A cultura poderia também ser compreendida como um conjunto de ações que dão uma nova dimensão social aos aspectos biológicos, "naturais" do nosso corpo. ${ }^{12}$

Os dados derivados do trabal ho do professor Edson sensibilizam-me a reconhecer que um conhecimento particular foi sendo tecido em interações dentro do contexto escolar. Por exemplo, parece-me que a contextualização das atividades originais foram baseadas em princípios relativos à relação espaço/tempo escolar, às normas, aos valores e às crenças que poderiam/deveriam ser questionados, à flexibilidade ou à rigidez da grade curricular, ao pensar e ser diferente, às práticas interativas em aula. Posso também ampliar a compreensão sobre conteúdo e forma assumidos por uma disciplina na prática pedagógica quando considero as forças e os interesses sociais que criaram condições para a vitória. É novamente com Lucíola Santos (1994) que aprendo que quando se discutem os estudos da história de uma disciplina não se pode considerar apenas o que ocorre em aula, o que levaria a uma visão muito restrita e mesmo deformada. U ma das condições, nessa história, seria a autonomia relativa do professor quando trabalha com disciplinas sem muito controle curricular, como é o caso de Saúde Pública que compõe a parte diversificada do currículo.

\section{A constituição de territórios conectando produção de conhecimento esco- lar e contexto CTS}

Ao pensar em questões como os processos de inovação curricular, identifiquei como insatisfatórias as análises que privilegiam a conversão do saber científico em saber escolar, centradas

\footnotetext{
11 "Podemos pensar sobre o currículo como criando regulação em dois diferentes níveis. Primeiramente a escolarização impõe certas definições sobre o que deve ser conhecido. Trata-se da questão spenceriana: qual conhecimento é mais válido? C ertas informações são selecionadas dentre uma vasta gama de possibilidades. Essa seleção molda e modela a forma como os eventos sociais e pessoais são organizados para a reflexão e a prática. ... Um diferente nível de regulação, um nível, para mim, fundamental para compreender as escolas, é o de que a seleção de conhecimentos implica não apenas informação, mas regras e padrões que guiam os indivíduos ao produzirem seu conhecimento sobre o mundo" (Popkewitz, 1994, p.192).

12 Para mais detalhes ver Santos $(1997,1999)$.
} 
nas características epistemológicas e de correção conceitual científicas que deveriam estar presentes no conhecimento escolar, marca da maioria de trabalhos que versam sobre contextos inovadores para o ensino, incluindo o CTS, como apontei no início deste artigo.

Buscando uma nova possibilidade de compreensão para o que ocorria em aula, encontrei idéias que concebem o currículo escolar como uma seleção cultural dos conteúdos julgados como válidos e verdadeiros em determinado contexto histórico por um grupo interessado. Posso, então, considerar que as representações de tecnologia, cultura e ciência e sua interface com a sociedade encontradas na prática do professor Edson estão também destacadas em outros campos sociais, além da escola. Por exemplo, a concepção de tecnologia do professor Edson atrela-se à noção de que seja uma conseqüência diante das necessidades para cura de doenças, prolongamento da vida, melhoria das condições de vida da população, representações também preponderantes nos materiais didáticos de uso no cotidiano escolar, que por sua vez são produto de uma cultura diferente, que é a do campo editorial.

Caminhando em outra direção, na tentativa de traçar o mapa das relações que podem ser estabelecidas na explicação do trabalho do professor, considero que os conhecimentos mais facilmente integráveis ao currículo, sobretudo no nível da sala de aula, são aqueles que mais plenamente se adaptam ou mais facilmente se submetem a processos do tipo da transposição didática. Assim, esta seria uma outra interpretação para o fato de o professor ter trabalhado com determinadas concepções de tecnologia, de ciência e de cultura.

Imagino que ocorra uma produção de conhecimentos escolares e que isso se dê dentro de um contexto que propicia a participação de um conjunto variado de conteúdos que constróem percepções diferentes da realidade social, significando formatos diferentes de enquadramento dessa realidade, mutáveis, transitórios e passíveis de serem questionados.

As atividades que o professor desenvolveu em suas aulas de Biologia e de Saúde Pública constituíram, na dinâmica das relações entre formas e conteúdos, o que posso chamar de conhecimento escolar. Esse conhecimento pode ser visto como resultado da apropriação pe dagógica de conhecimentos produzidos por diferentes campos do saber. Baseando-me em Lucíola Santos (1993), compreendo que, no movimento de produção, o conhecimento escolar teve como conteúdo os conhecimentos derivados dos diferentes campos do saber e sua forma foi dada pelas diferentes teorias e princípios metodológicos no campo do ensino e da aprendizagem. Posso entender que as disciplinas pedagógicas estão diretamente relacionadas à forma do discurso pedagógico, ou seja, é através do conteúdo abordado por essas disciplinas que o conhecimento dos diferentes campos ganha o "status" do conhecimento escolar.

U ma outra explicação, também para essa situação das aulas do professor Edson, é possível ser realizada segundo Basil Bernstein (1996). Para este autor, o conhecimento escolar é entendido como o resultado de recontextualizações sucessivas do discurso de um campo intelectual ou de uma área de conhecimento. 0 discurso de um campo de conhecimento é deslocado de seu campo original e real ocado na escola, onde é recontextualizado de acordo com a gramática do aparelho escolar. N esse contexto, 0 campo pedagógico forneceria 0 conjunto de regras (discurso pedagógico) através das quais os discursos de outros campos se transformam em conhecimento escolar.

A proposição e análise dos processos de organização curricular a partir de novos paradigmas da educação científica - como é o caso do movimento CTS - ganham outras dimensões quando consideram a instância da aula como produtora de conhecimentos que necessariamente dialogam e (se) modelam na interação com os demais conhecimentos culturais 
propostos como necessários e pertinentes para a inovação do ensino das Ciências. Criam emolduramentos nas relações, sempre tensas, entre tradição e novo, formas e conteúdos, no processo de produção do conhecimento escolar. D este ponto, puxo fios produzidos em trabalho anterior debatido na IV Escola deVerão (Amorim, 1999) e que gerou al guns questionamentos, relativos particularmente à qualidade e à quantidade da mudança dos professores que participam de cursos de formação inicial ou continuada sobre ensino de Ciências em contextos não-tradicionais, como o das relações CTS. Tracei neste artigo um território em que respostas a esses tipos de inquietação podem ser vislumbradas. Brotam em superfícies heterogêneas nas quais as ações curriculares são visualizadas em metamorfoses.

Busco conexões para dar visibilidades a essa analogia, inspirando-me humildemente no propósito do "Marco Polo", de Ítalo Calvino (1997), no esplêndido As cidades inviśvies. U ma dessas cidades, a oculta O linda, transforma-se, aumenta o tamanho a cada momento que a olhamos pelo intermédio de lentes. Olhares atentos e instrumentalizados percebem que a O linda inicial, original, não permanece imóvel e torna-se, após um tempo, uma "cidade de tamanho natural, contida na primeira cidade: uma nova cidade que abre espaço em meio à primeira e impelea para fora" (p.119). N a metamorfose de 0 linda, as ve Ihas muralhas se dilatam levando consigo os bairros antigos, ampliados. A nova O linda, "em suas dimensões reduzidas conserva os traços e o fluxo da linfa da primeira O linda e de todas as 0 lindas que despontaram uma de dentro da outra" (p.120). Esse processo, a metamorfose de O linda, aproximo-o das definições de texto que Antonio Batista (1996) tece em seu trabaIho: 0 texto é igual a uma cidade antiga que, ao longo de sua história, foi invadida, destruída e reconstruída por diferentes conquistadores; é manuscrito medieval, em que se misturam, sem distinção, as vozes de seus autores, de seus comentadores, dos que o copiam, dos censores que o modificam e refazem...

\section{Referências bibliográficas}

AIKEN HEAD, G. The integration of ST S into science education. Theory into Practice, v.31, n.1, 1991 p.27-35.

AM ARAL, I. A. Currículo de ciências: das tendências clássicas aos movimentos atuais de renovação. In: BARRETO , E. S. S. (O rg.). O s currículos do ensino fundamental para as escolas brasileiras. Campinas: Autores Associados: São Paulo: Fundação C arlos Chagas, 1998. p.201-232.

AM O RIM , A. C. R. Trajetória metodológica de professores de ciências sob a ótica das interações entre forma e conteúdo. Congresso iberoamericano de Educación en Ciencias Experimentales, II, Atas... Universidade de La Serena, La Serena, C hile: 1998a. p.112-4. . Biologia, tecnologia, cultura: inspirações para analisar a produção de conhecimento na escola. Reunião Anual da Associação N acional de Pós-Graduação em Educação, 21, Grupo de trabalho: Currículo. Setembro de 1998b. 5p. D isponível em «ttp://www.ufrgs.br/faced/gtcurric

- Avaliar e dimensionar a prática científica e tecnológica: contexto para aulas de ciências. Iñ: Escola de verão para Professores de Prática de Ensino de Feisica, Q uímica e Jiologia, 4, Atas... Universidade Federal de U berlândia, U berlândia, 1999 p.67-75.

. O s ol hares do caminhante nos territórios do ensino de biologia. Tese (D outorado em Ëducação). Faculdade de Educação;; U niversidade Estadual de C ampinas. Campinas, 2000. 
AM O RIM , A. C. R. El cuerpo humano en las dimensiones biológica y cultural: tema para clases de Biología. Revista de Educación en Biología. v.3, n.2, outubro de 2000b. 14p. (aceito para publicação)

BATISTA, A. A. G. Sobre o ensino de português e suas investigação: quatro estudos exploratórios. Tese (D outorado em Educação), Faculdade de Educação, Universidade Federal de M inas G erais, Belo H orizonte, 1996.

BECERRA, A. G. El tránsito desde la ciencia básica a la tecnología: la Biología como modelo. Revista I beroamericana de Educación, n.18, 1998. p.91-106.

BEN JAM IN , W. O bras Escolhidas: M agia e técnica, arte e política. 4.ed. São Paulo: Brasiliense, 1985.

BERN ST EIN , B. A estruturação do discurso pedagógi co: classe, código e controle. Tradução: Tomaz Tadeu da Silva e Luís Fernando Gonçalves Pereira. Petrópolis: Vozes, 1996.

BIZZO, N . et al. Encontro Perspectivas do Ensino de Biologia, 6, Coletânea... Campinas: Gráfica Central, Universidade Estadual de Campinas, 2000.

BRAGAW, D. H. Society, technology, and science: Is there room for another imperative? Theory into Practice, v.31, n.1, 1992. p.4-12.

BRU SIC, S. A. Achieving ST S goals through experiential learning. Theory into Practice, V.31, n.1, 1992. p.44-51.

BYBEE, R. W. Science-Technology-Society in science curriculum: The policy-practice gap. Theory into Practice, v.30, n.4, 1991. p.294-302.

CALVIN O, I. As Cidades Invisíveis. Tradução: Diogo M ainardi. São Paulo: Companhia das Letras, 1997.

CARTER, C. Science-Technology-Society and access to scientific knowledge. Theory into Practice, v.30, n.4, 1991. p.273-279.

FU LLICK, P. Addressing science and technology issues in the United Kingdom: The SAT IS Project. Theory into Practice, v.31, n.1, 1992. p.36-43.

H URD, P. D. Closing the educational gaps between science, technology and society. Theory into Practice, v.30, n.4, 1991. p.251-8.

MARAN DIN O, M., AM ORIM, A. C. R., KAWASAKI, C. S. (O rgs.). Coletânea do VII Encontro "Perspectivas do Ensino de Biologia" el Simpósio Latino-americano da IOSTE. São Paulo, 2 a 4 de fevereiro de 2000.849p.

M EGID NETO, J. (Coord.). 0 Ensino de Ciências no Brasil: catálogo analítico de teses e dissertações: 1972-1995. Campinas: U N ICAM P/FE/CED O C, 1998.

. Tendências das Pesquisa Acadêmica sobre o Ensino de Ciências no N ível Fundamental. Tese (D outorado em Educação), Faculdade de Educação, Universidade Estadual de Campinas, Campinas, 1999.

M OREIRA, M. A. et al. (O rg.) Atas do I Encontro Nacional de Pesquisa em Ensino de Ciências. Porto Alegre: Instituto de Física da UFRGS, 1997.

M OREIRA, M . A. e OSTERM AN N , F. (O rgs.). Atas do II Encontro $\mathrm{N}$ acional de Pesquisa em Educação em Ciências. Porto Alegre: Instituto de Física da U FRGS, 1999.

O LIVEIRA, M . R. N . S. Didática: Ruptura, Compromisso e Pesquisa. Campinas: Papirus, 1993. p.131-41.

O LIVEIRA, D . L. (O rgs). Ciências nas salas de aula. Porto Alegre: M edição, 1997, p.97112. 
PO PKEW IT Z, T. S. H istória do Currículo, Regulação Social e Poder. In: SILVA, T. T. (O rg.). 0 sujeito da educação: Estudos Foucaultianos. 2.ed. Petrópolis: Vozes, 1994. p.173210.

SAN TOS, L. L. C. P. Poder e Conhecimento: a constituição do saber pedagógico. In: O LIVEIRA, M .R.N.S. Didática: Ruptura, C pmpromisso e Pesquisa. Campinas: Papirus, 1993, p.131-41.

SAN TO S, L. H. S. Incorporando outras representações culturais de corpo. In: O LIVEIRA, D. L. (O rg.). Ciências nas salas de aula. Porto Alegre: M ediação, 1997. p.97-112. . Pedagogias do corpo: representação, identidade e instância de produção. In: SI LVA, L.'H. (Ō rg.) Século XXI: Q ual conhecimento? Q ual currículo? Petrópolis: Vozes, 1999. p.194212.

SAN TO S, L. L. C. P. H istória das D isciplinas Escolares: outras perspectivas de análise. In: Encontro de D idática e Prática de Ensino, 7, G oiânia, GO ,1994. p.158-65.

WORT M AN N, M . L. C. Currículo e Ciências - As Especificidades Pedagógicas do Ensino de Ciências. In: COSTA, M . V. (O rg.). 0 currículo nos Limites do Contemporâneo. Rio de Janeiro: DP\&A, 1998. p.129-58. 
